\title{
Obesity and the Respiratory System: New Methods to Examine an Old Question
}

\author{
Marc H. Lavietes \\ Pulmonary and Critical Care Medicine, University Hospital, Newark, N.J., USA
}

The prevalence of obese adults is approximately $25 \%$ of the population in most countries of Western Europe [1]. More disquieting, as many as $55 \%$ of adults in the United States are overweight [2]. Obesity is the second leading cause of preventable deaths in that it predisposes people to hypertension, dyslipidemia, coronary artery disease, diabetes, and other diseases as well.

Respiratory system manifestations of obesity, such as the obesity-hypoventilation syndrome (OHV) and obstructive sleep apnea, are less common but nevertheless of great clinical importance. The manner in which the respiratory and circulatory systems interact in obesity to cause alveolar hypoxia, pulmonary hypertension, and right ventricular failure is well documented in an older study [3]. Only a small percentage of people with severe obesity present with pulmonary disease, however. Attempts to identify those factors which predispose obese people to respiratory system dysfunction are of both academic interest and clinical use.

The possibility that cardiopulmonary failure occurs only in those overweight subjects with predominately truncal obesity has often been raised. In this issue of Respiration De Lorenzo et al. [4] propose the technique of dual-energy-X-ray absorptiometry (DXA) as a tool to study body composition and fat distribution in man. They document in 16 obese subjects (none apparently with cardiopulmonary failure) both a positive correlation between lean body mass and lung volumes and a decrease in fat mass accompanying weight loss. Moreover, they note that the decrease in fat mass was sustained by a decrease in upper body fat.

\begin{tabular}{ll}
\hline KARGER & ( 1999 S. Karger AG, Basel \\
Fax +4161306 12 34 & Accessible online at: \\
$\begin{array}{l}\text { E-Mail karger@karger.ch } \\
\text { www.karger.com }\end{array}$ & http://BioMedNet.com/karger
\end{tabular}

Their paper raises intriguing questions. Is there a statistical relationship between the loss of upper body fat and the increase in vital capacity after weight loss? How would these data compare with data obtained from obese subjects who clearly did manifest OHV? Would the $\mathrm{FM}_{\mathrm{TRN}} /$ body height ratio be a better index with which to assess the effect of obesity upon respiratory mechanics than an $\mathrm{FM}_{\mathrm{TRN}} / \mathrm{FM}_{\mathrm{TOT}}$ ratio? After all, the former ratio would serve as an index of the rotund body shape we empirically associate with OHV. How do DXA measurements compare as predictors of lung volume with simple measures of circumference and height which were also presented in the paper of de Lorenzo et al. [4]? Finally, would observations made with the DXA technique correspond to any genetic markers of obesity [5].

De Lorenzo et al. [4] have put forth a bold challenge to the pulmonary community to enhance our understanding of the relationship between obesity and cardiopulmonary dysfunction.

\section{References}

1 WHO Consultation on Obesity (Geneva, June 3-5, 1997).

2 NHLBI: Clinical Guidelines on the Identification, Evaluation, and Treatment of Overweight and Obesity in Adults. The Evidence Report. Washington, NIH (NHLBI), 1998.

3 Rochester DF, Enson Y: Current concepts in the pathogenesis of the obesity-hypoventilation syndrome. Am J Med 1974;57:402-420.

4 De Lorenzo A, Petrone-De Luca P, Sasso GF, Carbonelli MG, Rossi P, Brancati A: Effects of weight loss on body composition and pulmonary function. Respiration 1999;66:407-412.

5 Ronneman T, Karonen SL, Rissanen A, Koskenvuo M, Koivisto, VA: Relation between plasma leptin levels and measures of body fat in identical twins discordant for obesity. Ann Intern Med 1997;126:26-31.
Marc H. Lavietes, MD

University Hospital (I 354)

Pulmonary and Critical Care Medicine

150 Bergen Street

Newark, NJ 07103-2406 (USA) 